\title{
Delimitação de áreas prioritárias para a conservação da natureza na bacia do rio Mouräa-PR, sob a perspectiva do planejamento da paisagem
}

\section{Identifying priority areas for conservation of nature in the river basin Mourão- -PR, from the perspective of landscape planning}

\author{
Bruna Scipioni * \\ Maristela Denise Moresco Mezzomo ** \\ Vanessa Medeiros Corneli ***
}

\begin{abstract}
Resumo:
O Planejamento da Paisagem, aplicado nos estudos integrados da paisagem, se constitui como uma ferramenta que pode ajudar a planejar as atividades humanas, potencializando a conservação da natureza. Nesta perspectiva, este estudo tem como objetivo identificar áreas prioritárias para conservação da natureza na bacia do rio Mourão, no estado do Paraná, aplicando os pressupostos teórico-metodológicos do Planejamento da Paisagem. Para a delimitação das áreas prioritárias, foi feito a caracterização da paisagem da bacia, a delimitação de 4 unidades de paisagem, a classificação da cobertura vegetal e a localização de unidades de conservação. A correlação destas informações levou a definição de 2 áreas prioritárias para a conservação da natureza na bacia.
\end{abstract}

\section{Abstract:}

The Landscape Planning, applied to the integrated study of the landscape, is a tool that can help in the planning of human activities, enhancing nature conservation. In this perspective, this study aims to identify priority areas for nature conservation in the basin Mourão, in the state of Paraná, applying the theoretical and methodological assumptions of Landscape Planning. For the definition of priority areas, was made the characterization of the landscape of the basin, the delimitation of 4 landscape units, the classification of vegetation and the location of protected areas. The correlation of this information led to the definition of two priority areas for nature conservation in the basin.

\begin{abstract}
* Mestranda dem Engenharia de Recursos Hídricos e Ambiental da UFPR

** $\operatorname{Prof}^{\mathrm{a}} \operatorname{Dr}^{\mathrm{a}}$ do Departamento de Engenharia Ambiental da Universidade Tecnológica Federal do Paraná (UTFPR)campus Campo Mourão. Líder do Grupo de Pesquisa em Geoecologia e Gestão Ambiental.

*** $\operatorname{Prof}^{\mathrm{a}} \operatorname{Dr}^{\mathrm{a}}$ do Departamento de Engenharia Ambiental da Universidade Tecnológica Federal do Paraná (UTFPR)campus Campo Mourão.
\end{abstract}

Palavras-chave:

Cobertura Vegetal, Unidades de Conservação, Planejamento

Key-Words:

Vegetal cover, Conservation units, Planning 


\section{INTRODUÇÃO}

preocupação com os elementos naturais que Isão explorados pelo homem está diretamente relacionada ao tema conservação da natureza, o qual está cada vez mais inserido nas ações práticas da sociedade, como no caso da criação de leis ambientais. É o caso da Lei Federal n . 9.985/00 (BRASIL, 2000) que institui o Sistema Nacional de Unidades de Conservação da Natureza (SNUC), que tem por finalidade a gestão de Unidades de Conservação, visando à preservação, a manutenção e a utilização sustentável da natureza.

Além desta lei, existem outras ações como a aplicação do Código Florestal, Lei no 12.651 de 2012 (BRASIL, 2012). A junção destas leis pode promover a garantia de áreas verdes e consequentemente, a ampliação da proteção do solo e das águas. Para tanto, há necessidade de que as ações práticas que estas leis envolvem sejam executadas de forma planejada, já que um dos motivos para o desencadeamento de problemas ambientais é o uso dos elementos naturais de forma desordenada (CUNHA; MENDES, 2005).

Nesta perspectiva, pesquisas que tem como base teórico-metodológica o Planejamento da Paisagem, visam, entre outros aspectos, o mapeamento de áreas prioritárias para a conservação da natureza, auxiliando na escolha de novas áreas, e assim, potencializando a função de conservação exigida pelas leis ambientais.

Considerando, portanto, a importância do planejamento das atividades antrópicas diante dos elementos e recursos naturais, o objetivo deste artigo é apresentar um estudo de caso que determinou áreas prioritárias para a conservação da natureza na bacia do rio Mourão, na região centro-ocidental do Paraná.

Esta bacia abrange seis municípios, sendo eles Peabiru, Quinta do Sol, Engenheiro Beltrão, Campo Mourão, Luiziana e Mamborê e apresenta representatividade em diversos aspectos como no abastecimento de água na região, captação para irrigação agrícola e produção de energia.

A base teórico-metodológica do trabalho está fundamentada nos pressupostos do Planejamento da Paisagem, que se define pela aplicação de conceitos de organização territorial das atividades do homem sobre a paisagem (RODRIGUEZ; SILVA, 2013). A aplicação dos princípios e bases teóricas do Planejamento da Paisagem pode ser feito de diversas formas, como no caso do estudo e delimitação de unidades de paisagem tendo como foco a conservação da natureza, foco deste trabalho.

\section{FUNDAMENTANDO ALGUNS CONCEITOS}

Os principais conceitos utilizados para fundamentar o trabalho aqui apresentado envolvem paisagem, planejamento da paisagem, unidades de paisagem e unidades de conservação.

As unidades de conservação são áreas fixas, delimitadas e reconhecidas legalmente, se constituindo como um espaço territorial com recursos ambientais que apresentam características naturais relevantes. No Brasil, estas áreas compõem o Sistema Nacional de Unidades de Conservação que agrega unidades federais, estaduais e municipais, sendo composto por 12 categorias cujos objetivos específicos se diferenciam quanto à forma de proteção e usos permitidos (BRASIL, LEI 9.985/2000).

Já as unidades de paisagem, podem variar seus limites territoriais, sendo utilizadas como recorte espacial com foco no ordenamento e planejamento territorial, não sendo, portanto, criadas por lei, fixas e/ou perpétuas.

Para Beroutchachvilli e Bertrand (1978), as unidades são reconhecidas como o resultado da conjunção de fatores distintos, como a história geoecológica, a morfogênese do relevo, o clima em seu movimento, a dinâmica biológica e a participação da ação humana em sua evolução histórica.

Neste sentido, as unidades de paisagem são uma forma de representar as situações de determinado ambiente a partir da aproximação de características homogênea, o que cria e distingui espaços heterogêneos.

A relação entre unidades de conservação e unidades de paisagem no âmbito deste trabalho está no caráter territorial de reconhecimento de áreas potenciais para a conservação da natureza, que posteriormente mapeadas, podem ser concretizadas por meio da criação de unidades de conservação. As unidades de paisagem se constituem assim, dentro do entendimento metodológico do planejamento da paisagem, como uma ferramenta para delimitação de áreas com características homogêneas, as quais individualmente apresentam potencialidades e fragilidades distintas.

Neste contexto, a paisagem, em suas mais variadas formas de aplicação conceitual, é compreendida a luz da visão sistêmica, integrando sociedade e natureza de forma direta. Conforme Monteiro (2000), a paisagem é uma entidade espacial delimitada em uma condição de resolução para o pesquisador, assim sendo sempre o resultado da integração dinâmica, e instável dos elementos de composição (físicos, biológicos e antrópicos), mostrada em partes delimitáveis, 
mas individualizadas entre suas relações que se organizam em um todo complexo.

Este entendimento conceitual permite com que se aplique o conceito de Planejamento da Paisagem, compreendido como uma ferramenta no que diz respeito à organização do espaço (NUCCI, 2010). Vem sendo utilizado em diversos países, estando previsto em lei no caso da Alemanha, onde houve considerável incentivo a estudos da paisagem tendo como enfoque questões de proteção dos recursos naturais. No Brasil, alguns estudos que aplicam os fundamentos do Planejamento da Paisagem e análise integrada dos elementos com a finalidade de indicar melhorias são Marques (2007), Valaski (2008), Nucci (2008), Nucci (2010) e Mezzomo (2013).

Em Nucci (2008), o autor descreve que atualmente, ainda existem estudos em esferas diferentes do planejamento, com posterior tentativa de resumos parciais, a fim de propor medidas de planejamento do espaço. Porém, o que vem acontecendo é que no resultado final, nem todos os elementos estudados são considerados na decisão.

Neste sentido, o Planejamento da Paisagem é visto como o valor ecológico e a caracterização particular dos elementos da paisagem dentro de cada ambiente. Um alicerce deste estudo é a observação e compreensão das potencialidades da paisagem, definidas por suas aptidões e limites. A identificação desses limites e aptidões pode ser integrada as ações de planejamento e gestão ambientais, necessitando assim, considerar a importância particular da diversidade das paisagens como um fator fundamental no enriquecimento da qualidade de vida em uma determinada região (PUGLIELLI NETO, 2010).

O desenvolvimento teórico-metodológico e prático alcançado pela Ciência da Paisagem proporciona uma base sólida para a análise sistêmica do espaço, permitindo classificar e delimitar unidades homogêneas por suas características que podem ser estudadas, avaliadas e gerenciadas no próprio processo de planejamento do espaço (SALINAS CHAVEZ, 1998 apud FÁVERO et al., 2007).

Uma forma de elaborar o planejamento envolve o conceito de unidades de paisagem. Conforme Amorim et al. (2008) e Estêvez et al. (2011), uma unidade de paisagem se caracteriza como uma forma de representar as características, riscos e problemas de um determinado recorte espacial, por meio de análises das características homogêneas que diferenciam espaços heterogêneos. Isso permite o estudo dos elementos naturais e antrópicos em escala local, suas correlações e comportamentos demonstrando seus limites e aptidões em recortes espaciais distintos.

Este modelo de delimitação espacial proporciona também, a identificação de fragilidades ambientais e apresenta elementos essenciais na gestão territorial, que se constitui como uma maneira de disciplinar as ações antrópicas vinculados ao planejamento. Pode ainda, contribuir na avaliação de impactos ambientais, avaliação de recursos naturais, reconhecimento de áreas de riscos geoambientais, avaliação da vulnerabilidade de áreas à ocorrência de eventos naturais que possam proceder em quadros de impactos desastrosos e mapeamento de áreas de conservação (AMORIN; OLIVEIRA, 2008).

\section{MATERIAIS E MÉTODOS}

Para que fosse feita a identificação de áreas prioritárias para a conservação da natureza, foi necessário realizar a caracterização da paisagem, descrevendo as características da área de estudo em relação aos seus elementos como: solo, relevo, geomorfologia, geologia, fitogeografia e uso de solo. Posteriormente, foi feita a delimitação da bacia em unidades de paisagem para facilitar a localização espacial das áreas prioritárias. Após isto foi feita a classificação da cobertura vegetal através de análise de mapas para posterior definição de áreas prioritárias para a conservação da natureza.

\subsection{Caracterização da Paisagem}

A bacia hidrográfica do rio Mourão está inserida no sistema hidrográfico do rio Ivaí e drena $1.534 \mathrm{~km} 2$ de área (Figura 1). A escolha desta área se justifica pelo fato da bacia apresentar importância em termos socioeconômicos para seis municípios, sendo eles: Mamborê, Luiziana, Campo Mourão, Peabiru, Engenheiro Beltrão e Quinta do Sol, localizados na região centro-ocidental paranaense. A bacia é representativa em termos de abastecimento de água, captação de água para irrigação na zona rural, além da produção de energia elétrica, tendo uma Usina Hidrelétrica (Usina Mourão I) e uma PCH (Pequena Central Hidrelétrica Salto Natal), ambas instaladas no rio Mourão, principal rio da bacia.

A caracterização da paisagem da bacia (rocha, solo, relevo, hidrografia, fitogeografia, clima e uso e ocupação do solo), foi conduzida por meio de pesquisa bibliográfica, levantamento de informações e dados em sites de órgãos públicos como IAP (Instituto Ambiental do Paraná), MINEROPAR (Serviço Geológico do Paraná), IAPAR (Instituto Agronômico do Paraná), ITCG (Instituto de Terras 
Cartografia e Geociências), EMBRAPA (Empresa Brasileira de Pesquisa Agropecuária) e utilização de materiais cartográficos do banco de dados do Laboratório de Geoprocessamento - LABGEO da Universidade Tecnológica Federal do Paraná, campus Campo Mourão.

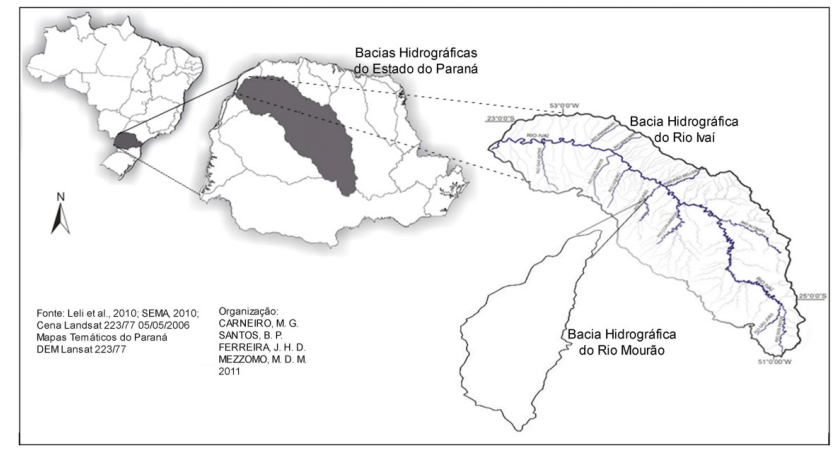

Figura 1 - Croqui de localização da bacia do rio Mourão. Fonte: Mezzomo, (2013).

A caracterização da paisagem da bacia (rocha, solo, relevo, hidrografia, fitogeografia, clima e uso e ocupação do solo), foi conduzida por meio de pesquisa bibliográfica, levantamento de informações e dados em sites de órgãos públicos como IAP (Instituto Ambiental do Paraná), MINEROPAR (Serviço Geológico do Paraná), IAPAR (Instituto Agronômico do Paraná), ITCG (Instituto de Terras Cartografia e Geociências), EMBRAPA (Empresa Brasileira de Pesquisa Agropecuária) e utilização de materiais cartográficos do banco de dados do Laboratório de Geoprocessamento - LABGEO da Universidade Tecnológica Federal do Paraná, campus Campo Mourão.

Os materiais utilizados foram: Atlas Geológico do Paraná, escala 1:250.000 (MINEROPAR, 2001); Atlas Geomorfológico do Paraná, escala 1:250.000 (Santos et al., 2006); Mapa de solos do estado do Paraná, escala 1:250.000 (Embrapa, 2007); Formações Fitogeográficas do Estado do Paraná, escala 1:2.000.000 (ITCG, 2009); Cartas temáticas da bacia do rio Mourão, na escala 1:50.000, dados STRM, 2000, UTM SAD 69, imagens Landsat 5 TM, cena: 223/76 e 223/77, fornecido pelo LABGEO (20 de junho de 2011); Atlas dos Remanescentes Florestais da Mata Atlântica, Datum SAD 69 na escala 1:250.000, (SOS Mata Atlântica, 2012) e Imagens do aplicativo Google Earth, para auxilio de visualizações de uso do solo.

\subsection{Delimitação de Unidades de Paisagem}

Optou-se por dividir a bacia hidrográfica em unidades de paisagem, para que se pudessem obter recortes espaciais distintos dentro da bacia. Entende-se que estes recortes permitem com que os projetos e ações de planejamento possam ser organizados e executados de forma mais pontual, considerando as especificidades, potencialidades e fragilidades. $\mathrm{O}$ uso do recorte de unidades de paisagem se apresentou como a melhor alternativa, uma vez que considera aspectos da paisagem como elementos norteadores e não critérios político administrativos.

Os critérios para a delimitação de unidades de paisagem devem partir do reconhecimento das relações existentes entre os elementos da paisagem de maneira que se destaque qual é mais significativo para a dinâmica daquele ambiente. Conforme Monteiro (2000) é possível utilizar um dos elementos da paisagem (relevo, clima, solo, geologia, etc.) como atributo de destaque e de maior significância para a dinâmica do ambiente, e assim estabelecer a delimitação das unidades. As tentativas de delimitação de unidades de paisagem devem considerar as características prevalecentes e valorizar as transições entre os compartimentos, não correndo o risco, assim, de generalização excessiva na escala considerada.

Neste sentido, a delimitação de unidades de paisagem foi feita por meio da análise das informações obtidas na primeira etapa (caracterização da paisagem). Esta análise demonstrou que em termos de clima e fitogeografia, a bacia apresenta homogeneidade, não servindo assim para o propósito da delimitação. As classes de solos apresentam variações que, conforme a escala utilizada levaria a compartimentação de vertentes, fugindo ao propósito do trabalho. O elemento hidrografia se destacou como interessante, uma vez que apresenta maior densidade no trecho inferior da bacia, porém, verificou-se que esta característica está associada ao elemento relevo, no que se refere a declividade, a qual se destaca na bacia quando comparados os trechos superior e inferior. Outra característica de destaque foi o substrato geológico, uma vez que parte da bacia está numa zona de transição entre duas bases geológicas. Este elemento foi considerado como um fator determinante para possíveis processos de fragilidade ambiental.

Diante desta análise, foram escolhidos dois elementos chaves que apresentam maior destaque na bacia e que seriam utilizados para a delimitação das unidades de paisagem: declividade e geologia.

As unidades assim denominadas de 1, 2 e 3, localizadas na parte inferior em direção a superior, em ordem crescente, tiveram como elemento chave a declividade. Para determinação do restante da bacia o elemento chave utilizado foi a geologia, delimitando assim a 4 unidade de paisagem. 
A declividade foi escolhida como fator determinante para a delimitação no caso de três unidades de paisagem, pois há certa delimitação natural, já que na parte superior da bacia, onde se localiza a unidade 3 , a declividade varia de 0 a $8 \%$. $\mathrm{Na}$ área correspondente a unidade 2 , os valores de declividade vão de 20 a 45\%, que se diferencia das demais áreas. A área da unidade 1 apresenta valores de 8 a 20\%, diferenciando da unidade 2 e da unidade 3.

A geologia determinou somente uma unidade, a unidade 4, definida pela característica geológica da região que tem como formação o Grupo Bauru, Formação Cauiá, que se difere do restante da bacia, sendo escolhida assim por sua característica comum aquela região.

\subsection{Identificação das áreas prioritárias para conserva- ção da natureza}

Após a delimitação de cada unidade de paisagem, foi feita a aplicação da delimitação sobre o mapa de Remanescentes Florestais, fornecido pela SOS Mata Atlântica (2012), para posterior definição das áreas prioritárias, por meio de um mapa confeccionado no software Spring 5.1.6 (INPE, 1996), com escala de 1:50.000.

Foi realizada a localização de unidades de conservação, bem como a identificação de cada categoria por meio de informações junto ao Instituto Ambiental do Paraná. Também foram identificados e localizados os remanescentes florestais na bacia do rio Mourão por meio do Atlas de Remanescentes Florestais da Mata Atlântica (SOS Mata Atlântica, 2012), e imagens do aplicativo Google Earth. Estes remanescentes florestais envolvem fragmentos florestais isolados e áreas de preservação permanente - APPs. A escolha por este último aspecto envolve o fato de que as APPs tem a função ambiental de preservar os recursos hídricos, a paisagem, a estabilidade geológica e a biodiversidade, facilitar o fluxo gênico de fauna e flora, proteger o solo e assegurar o bem-estar das populações humanas.

Após a localização das unidades de conservação e remanescentes florestais foi feita a aplicação da metodologia de Jim (1989) para classificação da vegetação (remanescentes florestais) da bacia com base na distribuição espacial, em três tipos principais, que são: Isolado, Linear e Conectado. Para isso foi feita uma adaptação da metodologia original alterando suas características de área urbana para área rural, bem como da escala, que passou a ser de menor detalhe, influenciando assim na troca da identificação de árvores para a identificação de fragmentos florestais (Figura 2).

Com a adaptação foram mantidas três classes de co- bertura vegetal originais, sendo elas: Isolado, Linear e Conectado e duas subclasses para cada classe, sendo:

* Isolado: a) Disperso: que tem fragmentos de cobertura vegetal dispersos pela área e distantes uns dos outros; b) Agrupado: fragmentos de cobertura vegetal mais próximos uns dos outros e em diferentes tamanhos;

* Linear: a) Retilíneo: que tem fragmentos de cobertura vegetal na forma mais retilínea seguindo uma conexão entre elas; b) Curvilíneo: os fragmentos estão em forma de curva contínua;

* Conectado: a) Reticulado: onde a cobertura vegetal se forma em retículos, caracterizando, por exemplo, áreas no entorno de rios; b) Contínuo: há uma continuidade e conectividade maior nos fragmentos de cobertura vegetal.

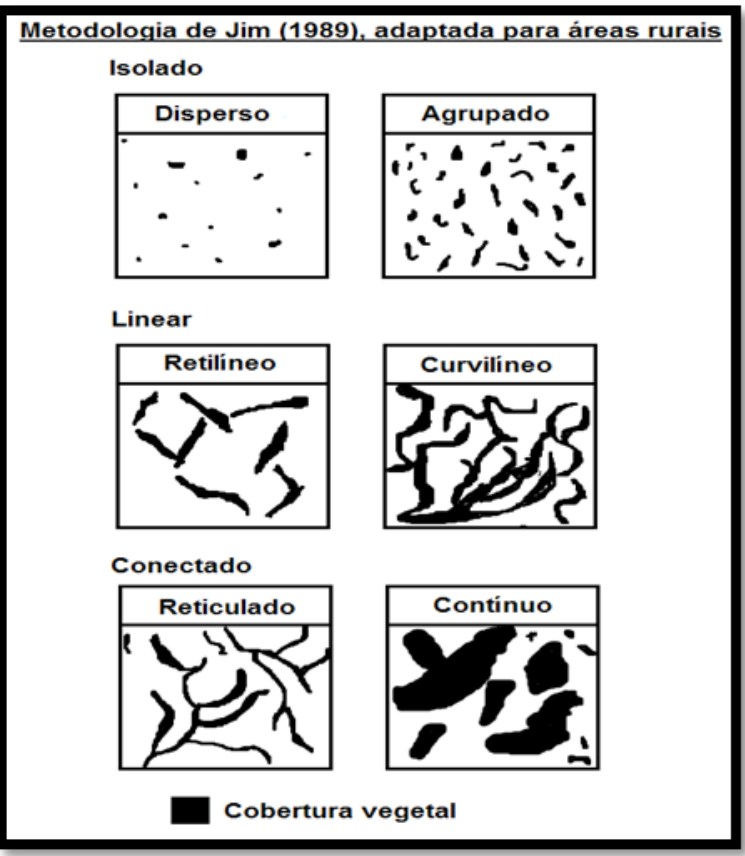

Figura 2 - Metodologia utilizada para classificação da vegetação (remanescentes florestais).Fonte: Jim (1989), adaptado.

Após esta etapa foi feito o cruzamento das informações entre classificação da vegetação (remanescentes florestais); a existência de unidades de conservação, uma vez que são fragmentos florestais já delimitados e protegidos por lei com intuito de conservar a natureza, podendo assim potencializar a criação de mosaicos de áreas protegidas; e a localização da cobertura vegetal para a conservação da natureza (mata ciliar, nascentes e áreas de forte declividade. Este cruzamento permitiu a localização e delimitação de áreas prioritárias para conservação em cada unidade de paisagem. Nesta 
etapa foi utilizado o Atlas de Remanescentes Florestais da Mata Atlântica obtido junto a SOS Mata Atlântica e LABOGEO/UTFPR, e o mapa de unidades de paisagem, que possibilitaram identificação e determinação das áreas prioritárias para conservação da natureza de cada unidade de paisagem.

\section{RESULTADOS E DISCUSSÃO}

As características de declividade e geologia podem ser visualizadas nas Figuras 3a e 3b, onde também é apresentada a delimitação das unidades de paisagem da bacia do rio Mourão. A distribuição dos remanescentes florestais, unidades de conservação e novamente a delimitação das unidades de paisagem estão na Figura 4. As unidades de paisagem foram caracterizadas em relação aos aspectos da paisagem (substrato rochoso, relevo, solo, fitogeografia), uso do solo e presença de unidades de conservação, conforme Quadro 1.

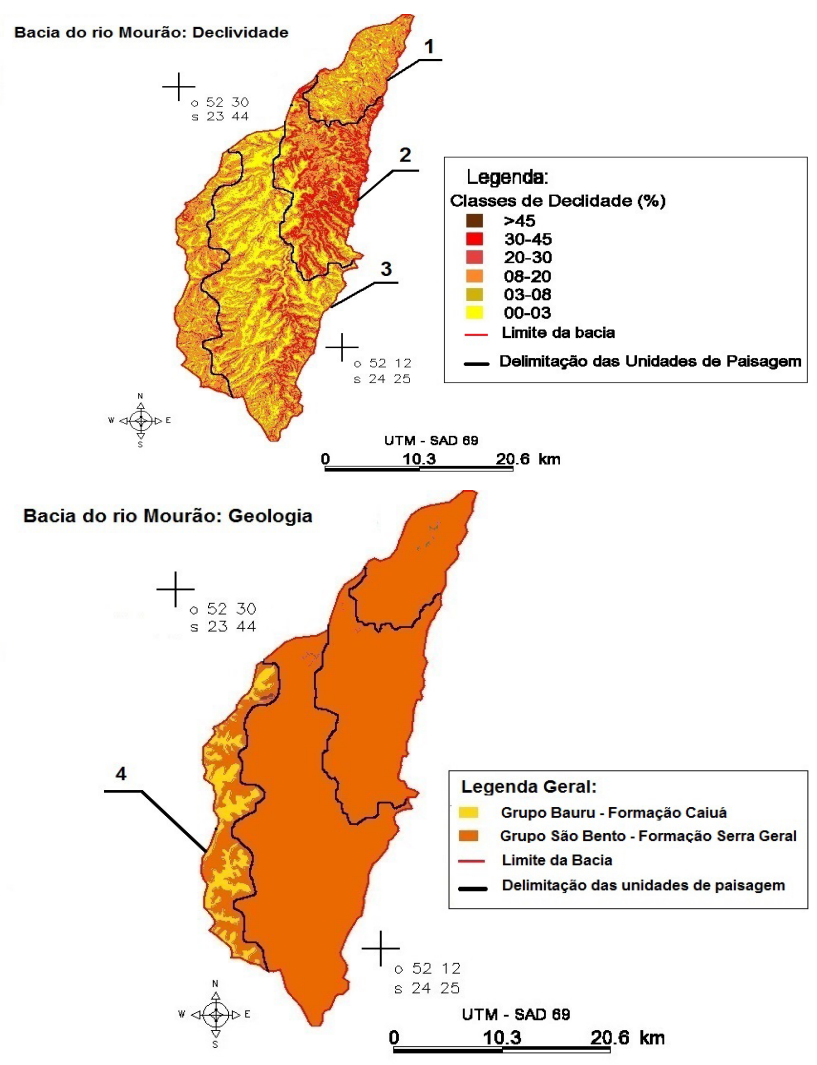

Figuras 3a e 3b - Delimitação de Unidades de Paisagem da bacia do rio Mourão, utilizando os elementos chaves declividade e geologia, respectivamente. Fonte: MINEROPAR (2001); LABGEO/UTFPR (2011).

A classificação da cobertura vegetal resultou na Figura 5, onde é possível verificar a distribuição da vegetação ao longo da bacia, bem como os grupos de classificação.

Para as unidades de paisagem 1 e 4 , definiu-se a classe de cobertura vegetal, dispersos, pois há poucas áreas com vegetação e estão dispersas umas das outras. Destaca-se uma pequena parte que se classifica como reticulado, por seguir a forma dos rios, na unidade de paisagem 4 .

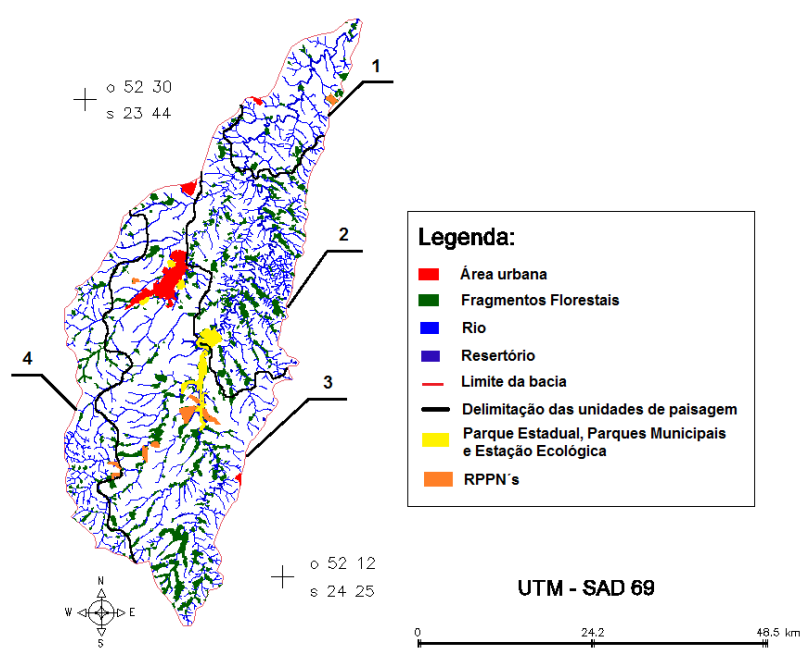

Figura 4 - Remanescentes Florestais, unidades de conservação e unidades de paisagem na bacia do rio Mourão. Fonte: SOS Mata Atlântica, (2012), adaptado.

$\mathrm{Na}$ unidade de paisagem 2, há uma área classificada como agrupado, devido ao fato da vegetação estar em fragmentos mais próximos umas das outras embora não de forma contínua. Outras duas áreas foram classificadas como retilíneo, por apresentarem características que enquadram a classe indicada, com cobertura vegetal em forma retilínea.

Já para a unidade de paisagem 3 existe uma área classificada como dispersa, justificada pelas áreas verdes estarem distantes umas das outras e em tamanhos menores. Outra parte desta unidade envolve uma área classificada como contínuo, por apresentar áreas verdes maiores e em forma contínua. Também apresenta outra área classificada como reticulado e contínuo, por estar seguindo a forma dos rios e com continuidade entre as áreas, sendo assim classificada nas duas classes ao mesmo tempo.

Assim, como objetivo final, integrando todas as informações apresentadas, foi possível delimitar 2 áreas de importância, definidas como áreas prioritárias para a conservação da natureza (Figura 0). Foram determinados alguns fatores de importância, como: a presença de unidades de conservação; a classificação da cobertura vegetal conforme a metodologia de Jim (1989), que classifica a cobertura vegetal pela quantidade, tamanho e proximidade entre elas; e a localização da cobertura vegetal em áreas prioritárias para a conservação da natureza, como áreas com mata ciliar, nascentes e áreas de forte declividade. 
Quadro 1 - Caracterização das Unidades de Paisagem

\begin{tabular}{|c|c|}
\hline \multicolumn{2}{|r|}{ UNIDADE DE PAISAGEM 1} \\
\hline Tamanho & $206,9 \mathrm{KM}^{2}$ \\
\hline $\begin{array}{l}\text { Substrato } \\
\text { rochoso }\end{array}$ & $\begin{array}{l}\text { Grupo São Bento - Formaçăo Serra Geral, efusivas básicas toleíticas com } \\
\text { basaltos maciços e amigdaloides, afaníticos, cinzentos a preto, raramente } \\
\text { andesíticos. Derrames de vulcanismos e fissura continental. }\end{array}$ \\
\hline Relevo & $\begin{array}{l}\text { Pertence a unidade morfoestrutural Bacia Sedimentar do Paraná, unidade } \\
\text { morfoescultural Terceiro Planalto Paranaense subunidade morfoescultural do } \\
\text { Planalto de Campo Mourão, com dissecação baixa. Apresenta gradiente de } \\
340 \text { metros com altitudes variando de } 260 \text { e } 600 \text { metros sobre o nível do mar. } \\
\text { As formas predominantes são topos aplainados, vertentes retilíneas e } \\
\text { côncavas na base e vales em calha, modelados em rochas da Formação Serra } \\
\text { Geral }\end{array}$ \\
\hline Solos & $\begin{array}{l}\text { Nitossolo vermelho eutroférrico típico, textura argilosa a moderado. Latossolo } \\
\text { vermelho distroférrico típico textura argilosa a moderado e proemineteálico. } \\
\text { Latossolo vermelho eutroférrico típico textura argilosa a moderado. }\end{array}$ \\
\hline Fitogeografia & Floresta Estacional SemidecidualSubmontana \\
\hline Uso do solo & $\begin{array}{l}\text { Unidade com uso do solo, predominantemente, feito por agricultura, com } \\
\text { partes da área com pastagem. }\end{array}$ \\
\hline $\begin{array}{l}\text { Unidade de } \\
\text { conservação }\end{array}$ & Uma Reserva Particular do Patrimônio Natural \\
\hline \multicolumn{2}{|r|}{ UNIDADE DE PAISAGEM 2} \\
\hline Tamanho & $418,9 \mathrm{~km}^{2}$ \\
\hline $\begin{array}{l}\text { Substrato } \\
\text { rochoso }\end{array}$ & $\begin{array}{l}\text { Grupo São Bento - Formação Serra Geral, efusivas básicas toleíticas com } \\
\text { basaltos maciços e amigdaloides, afaníticos, cinzentos a preto, raramente } \\
\text { andesíticos. Derrames de vulcanismos e fissura continental. E aluviöes em } \\
\text { pequenas porçōes, dispostos em planícies ao longo das drenagens e em } \\
\text { pequenas depressões alveolares fechadas. }\end{array}$ \\
\hline Relevo & $\begin{array}{l}\text { Pertence a unidade morfoestrutural Bacia Sedimentar do Paraná, unidade } \\
\text { morfoescultural Terceiro Planalto Paranaense subunidade morfoescultural do } \\
\text { Planalto de Campo Mouräo, com dissecaçāo baixa. Apresenta gradiente de } 340 \\
\text { metros com altitudes variando de } 260 \text { e } 600 \text { metros sobre o nivel do mar. As } \\
\text { formas predominantes são topos aplainados, vertentes retilineas e côncavas na } \\
\text { base e vales em calha, modelados em rochas da Formaçāo Serra Geral. }\end{array}$ \\
\hline Solos & $\begin{array}{l}\text { Neossolo litólico eutrófico típico textura média a moderado. Nitossolo vermelho } \\
\text { eutroférrico típico textura argilosa a moderado. Latossolo vermelho distroférrico } \\
\text { tipico textura argilosa a moderado. Nitossolo vermelho distroférrico típico } \\
\text { textura argilosa a proeminente álico }\end{array}$ \\
\hline Fitogeografia & Floresta Estacional Semidecidual Montana e Submontana \\
\hline Uso do solo & $\begin{array}{l}\text { Unidade com uso agrícola predominando, porém com porção maior de áreas } \\
\text { com pastagens do que as outras Unidades de Paisagem. }\end{array}$ \\
\hline $\begin{array}{l}\text { Unidade de } \\
\text { conservaçâo }\end{array}$ & Parte do Parque Estadual Lago Azul \\
\hline \multicolumn{2}{|r|}{ UNIDADE DE PAISAGEM 3} \\
\hline Tamanho & $781,6 \mathrm{~km}^{2}$ \\
\hline $\begin{array}{l}\text { Substrato } \\
\text { rochoso }\end{array}$ & $\begin{array}{l}\text { Grupo Săo Bento - Formação Serra Geral, efusivas básicas toleíticas com } \\
\text { basaltos maciços e amigdaloides, afaníticos, cinzentos a preto, raramente } \\
\text { andesíticos. Derrames de vulcanismos e fissura continental. }\end{array}$ \\
\hline Relevo & $\begin{array}{l}\text { Pertence a unidade morfoestrutural Bacia Sedimentar do Paraná, unidade } \\
\text { morfoescultural Terceiro Planalto Paranaense subunidade morfoescultural do } \\
\text { Planalto de Campo Mourăo, com dissecaçăo baixa. Apresenta gradiente de } 340 \\
\text { metros com altitudes variando de } 260 \text { e } 600 \text { metros sobre o nível do mar. As } \\
\text { formas predominantes são topos aplainados, vertentes retilineas e côncavas na } \\
\text { base e vales em calha, modelados em rochas da Formaçäo Serra Geral. }\end{array}$ \\
\hline Solos & $\begin{array}{l}\text { Neossolo litólico chernossólico típico fase relevo forte ondulado e montanhoso } \\
\text { substrato rochas eruptivas básicas + Chernossolo argilúvico térrico saprolitico } \\
\text { em relevo forte ondulado, ambos com fase pedregosa e floresta tropical } \\
\text { subperenifólia + Nitossolo vermelho distroférrico típico a moderado, fase floresta } \\
\text { tropical perenifólia e relevo ondulado, todos com textura argilosa. } \\
\text { Neossololitölicoeutrófico tipico textura média a moderado. Latossolo vermelho } \\
\text { distroférico típico textura argilosa a moderado álico. Latossolo vermelho } \\
\text { eutroférrico típico fase relevo suave ondulado + Nitossolo vermelho eutroférrico } \\
\text { tipico fase relevo suave ondulado e ondulado, ambos textura argilosa a } \\
\text { moderado, fase floresta tropical perenifólia. }\end{array}$ \\
\hline Fitogeografia & Floresta Ombrófila mista montana, com araucárias e mata de pinheiros. \\
\hline Uso do solo & Unidade com uso quase que exclusivo de agric \\
\hline $\begin{array}{l}\text { Unidade de } \\
\text { conservação }\end{array}$ & $\begin{array}{l}\text { Cinco Reservas Particulares do Patrimônio Natural, uma Estação Ecológica, } \\
\text { dois Parques Municipais e parte do Parque Estadual Lago Azul. }\end{array}$ \\
\hline \multicolumn{2}{|r|}{ UNIDADE DE PAISAGEM 4} \\
\hline Tamanho & $241,2 \mathrm{~km}^{2}$ \\
\hline $\begin{array}{l}\text { Substrato } \\
\text { rochoso }\end{array}$ & $\begin{array}{l}\text { Formação Cauiá, Grupo Baurú com arenitos finos a médios, arroxiados. } \\
\text { Coluviōes arenosos a arenoargilosos derivados dos Arenitos Caiuá, dispostos } \\
\text { sobre espigõos ou rampas a meia encosta. Apresenta transição para o Grupo } \\
\text { São Bento, Formação Serra Geral. }\end{array}$ \\
\hline Relevo & $\begin{array}{l}\text { Pertence a unidade morfoestrutural Bacia Sedimentar do Paraná, unidade } \\
\text { morfoescultural Terceiro Planalto Paranaense subunidade morfoescultural do } \\
\text { Planalto de Campo Mourão, com dissecação baixa. Apresenta gradiente de } 340 \\
\text { metros com altitudes variando de } 260 \text { e } 600 \text { metros sobre o nível do mar. As } \\
\text { formas predominantes são topos aplainados, vertentes retilíneas e côncavas na } \\
\text { base e vales em calha, modelados em rochas da Formaçâo Serra Geral. }\end{array}$ \\
\hline Solos & $\begin{array}{l}\text { Latossolo vermelho distroférrico típico textura argilosa a moderado. Argissolo } \\
\text { vermelho distrófico abrúptico textura arenosa/média a moderado. Latossolo } \\
\text { vermelho distrófico típico textura média a moderado. }\end{array}$ \\
\hline Fitogec & Floresta Ombrótila mista montana, com araucárias e mata de pinheiros. \\
\hline Uso do solo & Unidade com uso agrícola predominante. \\
\hline $\begin{array}{l}\text { Unidade de } \\
\text { conservação }\end{array}$ & rimōnio Natural \\
\hline
\end{tabular}

$\mathrm{Na}$ unidade de paisagem 1, não foi identificada nenhuma área de importância levando em consideração os critérios determinados como limitantes. Esta situação ocorre devido ao fato de que esta unidade apresenta apenas uma
Unidade de Conservação, representada por uma RPPN, além de ter sua cobertura vegetal classificada como isolada de forma dispersa, com poucas áreas verdes e estando dispersas umas das outras. Tais características não se mostram relevantes para determinação de uma área prioritária para conservação da natureza, para este momento.

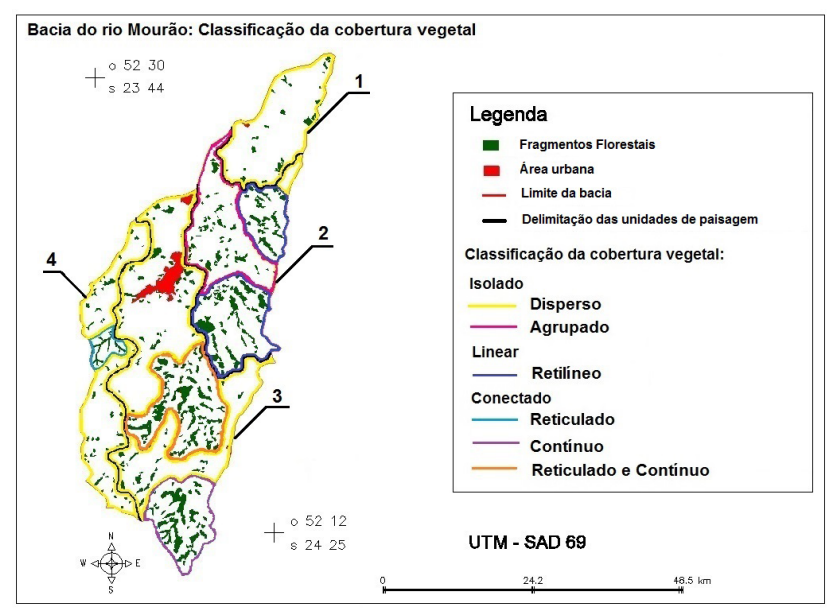

Figura 5 - Aplicação da metodologia de Jim (1989) para classificação da cobertura vegetal (remanescentes florestais) na bacia do rio Mourão. Fonte: SOS Mata Atlântica, (2012), adaptado.

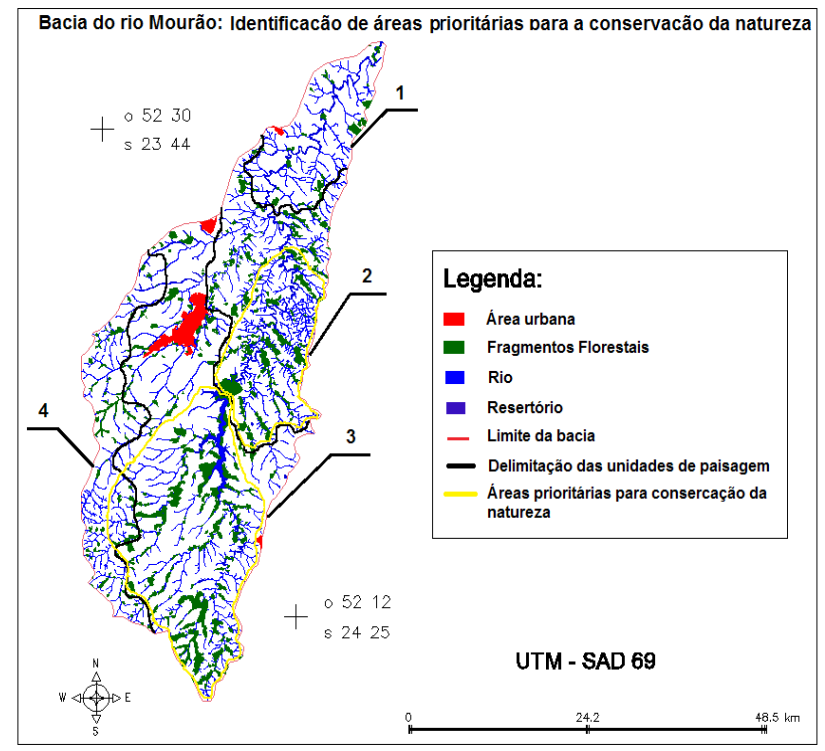

Figura 6 - Áreas prioritárias para a conservação da natureza na bacia do rio Mourão. Fonte: OS Mata Atlântica, (2012), adaptado.

A unidade de paisagem 2 apresenta uma área com importância para a conservação da natureza, de acordo com as características determinadas pela metodologia. A área determinada se situa no setor sudoeste da unidade estando próximo a uma Unidade de Conservação, o Parque Estadual Lago Azul. Além disso, a área apresenta classificação da cobertura vegetal do tipo linear e retilíneo. Outra informação relevante 
é sua declividade que apresenta valores de 20 a $45 \%$, considerado relevo forte ondulado, fator que aumenta a atenção necessária para a área, já que esta característica dificulta o uso da terra para atividades agrícolas e industriais, indicando ser uma área prioritária para a conservação da natureza.

Na parte sul da unidade de paisagem 3 , foi identificada uma área relevante para a conservação da natureza, pois apresenta maior quantidade de características de acordo com os critérios utilizados. É a área que tem maior quantidade de Unidades de Conservação, totalizando 6. A cobertura vegetal está classificada como conectado em duas partes, sendo contínuo no sul e reticulado contínuo em direção ao norte. Dessa forma mostra-se em áreas mais contínuas e conectadas entre elas, indicando maior facilidade para conservação da natureza. Sabendo que a conservação se torna mais efetiva se levado em conta tais características, pois quanto maior a área verde maior a diversidade. Além disso, a localização da cobertura vegetal ocorre nas encostas e beiras de rios e no entorno do reservatório da Usina Hidrelétrica Mourão I, o que justifica a possibilidade de ações voltadas à conservação da natureza nestas áreas.

Para a unidade de paisagem 4, há a continuação da área definida como prioritária na unidade de paisagem 3 , por estar próximo a RPPN, e da continuação do contorno dos rios, por isso entrou na definição da segunda área prioritária para a conservação da natureza. Não foi definida nenhuma outra área de relevância, pois analisando os fatores limitantes, a classificação da cobertura vegetal está como isolado, disperso em grande parte e reticulado em uma pequena área. Dessa forma não foram identificadas áreas prioritárias, nesta unidade de paisagem até o momento.

\section{CONSIDERAÇÕES FINAIS}

Tendo como base teórico-metodológica o Planejamento da Paisagem, o presente estudo teve como objetivo identificar e delimitar áreas prioritárias para a conservação da natureza na bacia hidrográfica do rio Mourão. $\mathrm{O}$ intuito foi indicar áreas que apresentam potencial conservador, tendo em vista potencializar ações já existentes, como no caso das unidades de conservação presentes na área, quanto identificar áreas possíveis de ser objeto de novas ações de conservação. Os critérios utilizados para definir as áreas foram: a classificação da cobertura vegetal, através do tamanho e distribuição das áreas verdes; a presença de Unidades de Conservação, sua localização e proximidades com outras áreas; e áreas com potencial para a conservação da natureza, como mata ciliar, nascentes e áreas de maior declividade.

Como resultado, foram delimitadas duas áreas prioritárias, estando estas localizadas no trecho superior da bacia, envolvendo parte do território das unidades de paisagem $2 \mathrm{e}$ 3. Estas áreas contam com a presença de 6 unidades de conservação, declividades mais acentuadas e maior concentração de cobertura vegetal, representados por fragmentos florestais isolados e áreas de preservação permanente.

De maneira geral, as informações e mapas gerados podem ser utilizado em outros estudos ou mesmo em projetos referentes à bacia hidrográfica, principalmente em relação a conservação da natureza, já que leva em conta critérios ambientais e orientações legais como as áreas de preservação permanente e as unidades de conservação, previstas no Código Florestal e no SNUC, respectivamente.

A indicação das áreas prioritárias para conservação da natureza se constitui assim, uma contribuição aos estudos ambientais da bacia do rio Mourão, cujos resultados também podem ser mais bem explorados no que tange a escala de análise, possibilitando estudos específicos de cada unidade de paisagem.

\section{REFERÊNCIAS BIBLIOGRÁFICAS}

AMORIM, R. R.; OLIVEIRA, R. C. de. As Unidades de Paisagem como uma categoria de análise geográfica: o exemplo do município de São Vicente-SP. Sociedade \& Natureza, Uberlândia, v. 20, n. 2, p. 117-198, dez. 2008.

BERTRAND, G. Paisagem e Geografia Física Global. Caderno de Ciências da Terra, São Paulo, Universidade de São Paulo, 1971. 27 p.

BEROUTCHACHVILI, N.; BERTRAND, G. Le gósystéme ou "Systéme territorial natural". Revue Geógraphique des Pyrenées et du Sud-Oest, 49 (2): 1967-1980, Toulouse, 1978.

BRASIL. Lei $\mathrm{n}^{\circ}$. 9.985, de 18 de julho de 2000. Regulamenta o art. 225, $\int 1^{\circ}$, incisos I, II, III e Vll da Constituição Federal. Institui o Sistema Nacional de Unidades de Conservação da Natureza: DOU de 19/7/2000. Disponível em: http://www.planalto.gov.br/ccivil_03/leis/L9985. htm. Acesso em: jun. 2013.

BRASIL. Lei $\mathrm{n}^{\circ}$. 12.651, de 25 de maio de 2012. Dispõe sobre a proteção da vegetação nativa; altera as Leis nos 6.938, de 31 de agosto de 1981, 9.393, de 19 de dezembro de 1996, e 11.428, de 22 de dezembro de 2006; revoga 
as Leis nos 4.771, de 15 de setembro de 1965, e 7.754, de 14 de abril de 1989, e a Medida Provisória no 2.166-67, de 24 de agosto de 2001; e dá outras providências: DOU de 28/5/2012. Disponível em: http://www.planalto.gov.br/ ccivil_03/_Ato20112014/2012/Lei/L12651compilado. htm. Acesso em: jun. 2013.

CUNHA, C. M. L. da; MENDES, I. A. Proposta de Análise Integrada dos Elementos Físicos da Paisagem: Uma abordagem Geomorfológica. Estudos Geográficos, Rio Claro n 3, p 111 - 120, Universidade Estadual Paulista, 2005.

EMBRAPA - Empresa Brasileira de Pesquisa Agropecuária. Mapas de solo do estado do Paraná: escala 1:250.000. Rio de Janeiro: Embrapa Solos, 2007.

ESTÊVEZ, L. F.; CUNICO, C.; MEZZOMO, M. M.; BIESEK, A. S.; MAGANHOTO, R. Análise da Paisagem da Bacia Hidrográfica do Rio Marumbi, Morretes - PR: Unidades de Paisagem, Fragilidade Potencial e Hemerobia. RA'E GA, Espaço Geográfico em Análise, Departamento de Geografia, UFPR, Curitiba, 2011, p. 428-447.

FÁVERO, O. A.; NUCCI, J. C.; BIASI, M. de. Delimitação de Unidades de Paisagem como subsídio ao planejamento da Bacia Hidrográfica do Rio Sorocaba/SP. In: Simpósio Brasileiro de Geografia Física Aplicada, 12. Anais... 2007, Rio Grande do Norte. Universidade Federal do Rio Grande do Norte, 2007. p. 510-227.

INPE. Instituto Nacional de Pesquisas Espaciais. SPRING: Integrating remote sensingand GIS by object-oriented data modeling. Camara G; Souza, R. C. M; Freitas U. M; Garrido J., Computers \& Graphics, 20: (3) 395-403, May-Jun 1996. Disponível em: http:/ /www.dpi.inpe.br/spring/portugues/index.html. Acesso em: set. 2013.

ITCG - INSTITUTO DE TERRAS, CARTOGRAFIA E GEOCIÊNCIAS. Formações fitogeográficas. 2009. Disponível em: http://www.itcg.pr.gov.br/arquivos/File/ Produtos_DGEO/Mapas_ITCG/PDF/Mapa_Fitogeografico_A3.pdf. Acesso em: jun. 2013.

JIM, C.Y. Tree-canopy characteristics and urban development in Hong Kong.The Geographical Review, v.79, n.2. Lawrence: American Geographical Society, pp. 210-255, 1989.

LABGEO- LABORATÓRIO DE GEOPROCESSA-
MENTO. Cartas Temáticas da bacia do rio Mourão. Escala 1:50.000, dados SRTM, 2000, imagens Landsat 5 - TM, cena 223/76 e 223/77. Universidade Tecnológica Federal do Paraná, campus Campo Mourão. 20 de jun. 2011.

MARQUES, A. C. Planejamento da paisagem da Floresta Nacional de Três Barras (Três Barras - SC): subsídios ao Plano de Manejo/Gestão. 2007. 132f. Dissertação (Mestrado em Geografia) Universidade Federal do Paraná, Curitiba, 2008.

MEZZOMO, M. D. M. Planejamento da Paisagem e Conservação da Natureza em RPPN's na Bacia Hidrográfica do Rio Mourão, Paraná. 2013. 264 f. Tese (Doutorado em Geografia) - Universidade Federal do Paraná, Curitiba, 2013.

MMA - MINISTÉRIO DO MEIO AMBIENTE. Avaliação e identificação de áreas e ações prioritárias para a conservação, utilização sustentável e repartição dos benefícios da biodiversidade nos biomas brasileiros. Brasilia: MMA/SBF, 2002. 404 p. Disponível em: http:// www.biodiversidade.rs.gov.br/arquivos/BiodiversidadeBrasileira_MMA.pdf. Acesso em: jun. 2013.

MINEROPAR - MINERAIS DO PARANÁ SA. Atlas Geológico do Paraná. Mineralogia do Paraná. Curitiba: Mineropar, 2001. Escala 1:650.000. Disponível em: http:// www.mineropar.pr.gov.br/arquivos/File/MapasPDF/ atlasgeo.pdf. Acesso em: jun. 2013.

MONTEIRO, C. A. F. Geossistemas: a história de uma procura. São Paulo: Contexto, 2000.127p.

NUCCI, J. C. Aspectos teóricos do Planejamento da Paisagem. In: Nucci, J. C. Planejamento da Paisagem como subsídio para a participação popular no desenvolvimento urbano. Estudo aplicado ao bairro de Santa Felicidade Curitiba/PR.Curitiba, Anais... LABS/DGEOG/UFPR, 2010. 277p. Disponível em: http://www.geografia.ufpr.br/ laboratorios/labs/?pg=publicacoes-php. Acesso em: jun. de 2013.

Qualidade ambiental e adensamento urbano. Curitiba: $2^{a}$ edição do autor (e-book), 2008. Disponível em: www.geografia.ufpr.br/laboratorios/labs. Acesso em: jun. 2013. 
PUGLIELLI NETO, H. F. Fragmentos Florestais e Conservação da Natureza em Santa Felicidade. In: Nucci, João C. (Org.). Planejamento da Paisagem como subsídio para a participação popular no desenvolvimento urbano. Estudo aplicado ao bairro Santa Felicidade - Curitiba/PR. LABS/DGEOG/UFPR, 2010. 277p.

RODRIGUEZ, J. M. M.; Silva, E. V. Planejamento e Gestão Ambiental: Subsídios da Geoecologia das Paisagens e da Teoria Geossistêmica. Fortaleza: Editora da UFC. 2013, 370 p.

SANTOS, L. J. C.; OKA-FIORI, C.; CANALI, N. E.; FIORI, A. P.; SILVEIRA, C. T.; SILVA, J. M. F.; ROSS, J. L. S. Atlas Geomorfológico do Estado do Paraná. Escala base 1:250.000, modelos reduzidos 1:500.000. Curitiba: MINEROPAR, 2006. 59p. Disponível em: http://www. mineropar.pr.gov.br/arquivos/File/2_Geral/Geomorfologia/Atlas_Geomorforlogico_Parana2006.pdf. Acesso em: jun. 2013.

SOS MATA ATLÂNTICA. Atlas dos Remanescentes Florestais da Mata Atlântica. Escala 1:50.000. Instituto Nacional de Pesquisas Espaciais (INPE), 2012. Disponível em: http://mapas.sosma.org.br/. Acesso em: out. 2013.

VALASKI, S. Avaliação da qualidade ambiental em condomínios residenciais horizontais com base nos princípios do planejamento da paisagem. Estudo de caso: bairro Santa Felicidade - Curitiba/PR. 2008. 152 f. Dissertação (Mestrado em Geografia) Universidade Federal do Paraná, Curitiba, 2008.
Correspondência das autoras:

$$
\begin{gathered}
\text { Bruna Scipioni } \\
\text { e-mail: brunascipioni@gmail.com } \\
\text { Maristela Denise Moresco Mezzomo } \\
\text { e-mail: mezzomo@utfpr.edu.br } \\
\text { VanessaMedeiros Corneli } \\
\text { e-mail: corneli.vanessa@gmail.com }
\end{gathered}
$$

Artigo recebido em: 25/04/2016

Revisado pelos autores em: 14/05/2016

Aceito para publicação em: 22/05/2016 